LETTERS TO THE EDITOR.

[The Editor does not hold himself responsible for opinions ex. pressed by his correspondents. Neither can he undertake to return, or to correspond with the weriters of, rejected manuscripts intended for this or any other part of NATURE. No notice is taken of anonymous communications.]

\section{The Use of Kites for Meteorological Observations in the Upper Air.}

Atтempts to use kites for meteorological observations in the upper air began more than a century ago. The lack of light instruments which record automatically and continuously, prevented the success of the early experimenters. Such records are now obtained for the first time by means of kites at the Blue Hill Meteorological Observatory, near Boston. A history of kite-flying for meteorological observations, with a general account of the work at the Blue Hill Observatory, was given by the Director, Mr. Rotch, in a paper read before the Physical Section of the British Association at the Liverpool meeting (1896). Notes in NATURE of October 22 and 29, vol. liv. pp. 598 and 629 , mention briefly the altitudes to $w$ wich a meteorograph has been lifted at Blue Hill during the past summer. A few of the details of the recent highest ascent may be of interest to the readers of NATURE, especially as it shows that clear and definite meteorological records can be obtained at a great height by means of kites, at a comparatively small expense. The meteorograph weighs three pounds, and records temperature, humidity, and atmospheric pressure. The record of October 8, from the earth's surface to an altitude of 9375 feet above sea level, was as clear and sharp as the records of similar instruments in thermometer screens at the observatory. The temperaturescale on the chart is centigrade, and the humidity pen records Io per cent. too low, so that 90 per cent. represents saturation. The barograph-pen is made to record altitudes in metre; but it went entirely off the scale, which is too small for the altitude reached. The record was, however, completed on the part of the chart above the scale. A determination of the altitude was made by placing the barograph under an air-pump, and finding the fall of pressure necessary to raise the barograph-pen to the highest point recorded when on the kite. From the amount of fall and the temperature recorded by the thermographs on the kite and at the observatory, the altitude was computed. The altitude was also computed from the angular elevation of the kites and the length of line recorded by a reel, 3 per cent. being allowed for the sag of the steel wire holding the kites. The amount of the sag was determined by previous theodolite measurement, from a long base line, of the altitude of the kites. The altitudes by the two methods agreed within I per cent. of the height, and the mean of the two is given. In this ascent nine kites with a total area of about 170 square feet and I8,000 feet of steel wire, weighing about 46 lbs., were used. All the work of the ascent was managed with an ordinary wooden windlass by the three members of the staffMr. Fergusson, Mr. Sweetland and myself. The sea-coast is about six miles from Blue Hill, and the general level of the surrounding land is about 100 feet above sea-level. The top of Blue Hill, from which the kites were flown, is 635 feet above sea-level. Cumulus clouds had begun to form when the ascent began, and the meteorograph was soon elevated to the cloudlevel, as shown by the humidity record, and was then lowered to remove a defective kite. In the second ascent the clouds were entered at an altitude of 4500 feet. The successive kites added to lift the line as they rose to the cloud-level, and again, when they were drawn below it, gave the data for numerous successive determinations of the altitude of the bases of the cumulus clouds, and furnish an example of the accuracy and frequency with which clouds can be measured in this manner, as shown by the following results :-

$\begin{array}{lcccccccccc} & \text { a.m. } & \text { p.m. } & & & & & & \\ \text { Time } \ldots . .11 .18 & \text { Ir. } & \text { 1.58 } & 2.05 & 2.39 & 3.01 & 3.34 & 3.36 & 4.34 & 4.57 & 5.23 \\ \text { Altitude } & 2974 \text { ft. } & 4500 & 464 \mathrm{6} & 5035 & 5405 & 5254 & 5097 & 5044 & 5000 & 5130\end{array}$

These measurements show that the level of the bases of the cumulus clouds rose steadily from I I a.m. to 3 p.m., then diminished slowly. Theodolite measurements at Blue Hill show this to be the normal daily course of the cumulus. The kitemeteorograph passed above the tops of the cumulus at $3.08 \mathrm{p} . \mathrm{m}$. and the humidity fell in a short time 46 per cent., showing a very dry air above the clouds; a condition which the meteoro- graph has shown in every case when it was lifted above the clouds, the fall of humidity usually being very rapid after the top of the cloud is passed.

The temperature on October 8 fell below the freezing point at $1.35 \mathrm{p} . \mathrm{m}$. at an altitude of 4540 feet, and continued below freezing until an altitude of 3850 feet was reached at 8.24 p.m. in the descent. At the highest point the recorded temperature was $10^{\circ}$ below the freezing point. At the Blue Hill Valley Station at this time the temperature shown by a thermograph was $49^{\circ} \mathrm{F}$, making a fall of $29^{\circ} \mathrm{F}$. in 9300 feet, or $I^{\circ}$ in 320 feet. This fall is slower than the average we have found, which is about $4^{\circ}$ in 1000 feet during the day-time, or $\mathrm{I}^{\circ}$ in 250 feet. During, and immediately preceding, decidedly colder weather the rate of fall increases to about $6^{\circ}$ in Iooo feet. The rate of fall is least preceding warmer weather, since a warm wave, as a rule, sets in first aloft.

The ease with which a meteorograph can be lifted to the height of a mile is shown by the fact that this was accomplished three times in four days during August in normal weather conditions. The highest point reached by no means represents the highest point attainable with kites, since at the time of the highest ascent the pull of the kites on the line was roo lbs., while the breaking strain of the line is over 300 lbs., so that had there been more wire on the reel a much greater altitude might have been reached. Three, or possibly four or five, miles does not seem unattainable in this nianner. The importance of such observations for the further developement of meteorology is shown by the fact that the weather conditions at the height of a mile above any station differ more from the weather at that station than does the weather at any place within 500 or 1000 miles at the level of the station on the earth's surface. At the height of a mile in the free air the temperature is usually from $15^{\circ}$ to $25^{\circ} \mathrm{F}$. colder than at the earth's surface, and there is virtually no daily change in temperature, the nights being as warm as the days. The only changes are due to the passage of warm and cold waves. During fair weather at this height the days are very damp, and the nights extremely dry. Low clouds frequently cover the earth, and even rain may fall from these while the sun shines bright at the height of a mile. The average velocity of the wind at this height is four times greater than at the ground, and hurricanes of 100 miles an hour are not uncommon. At least, che meteorograph records obtained by kites, and measurements of the heights and movements of clouds with theodolites, indicate that these are the conditions which exist above Blue Hill.

H. Helm Claytox.

Blue Hill Meteorological Observatory, Milton, Mass. U.S.A., November 20 .

\section{The Theory of Dissociation into Ions.}

Prof: Armstrong (page 78) says that the chief concern of chemists has been to establish facts; and perhaps this is true but to an outsider it has seemed recently as if some few facts were unwelcome to the school of chemists represented by himself. For instance, they seemed annoyed at one time with the inertness and the specific-heat-ratio of argon; now he expresses himself as if vexed with the slowness of ionic velocities, and "declines to accept it."

If the ions travelled quicker, a liquid would conduct better than it does, and perhaps that is what Prof. Armstrong desires; but it is difficult to see any ground for his objection to the present state of things. In a rare medium, like a gas, the ions migrate quickly ; in a dense medium, like a liquid, they migrate slowly; and their numerical speeds, as measured, exactly for liquids, approximately for air, are not inappropriate to the relative crowdedness. What more can be desired? The facts do not even demand much difference between the gaseous and liquid states; though even if they did they would still have to be accepted, just as the facts of viscosity and its contrary affection by temperature in the two states have been accepted.

I know very well, and have long known, that Prof. Armstrong objects to the idea of perfectly free ions; but surely he is aware that many physicists object to it too, with whatever glimmering of chemical instinct they possess, and they have endeavoured to show that the facts can be expressed without such an hypothesis. Physicists have also objected to the idea of a dissolved salt existing as a free gas in a solvent, notwithstanding the remarkable analogies with gaseous laws, discovered in an admirable manner by physical chemists, that such a substance presents;

No. I 4 I6, vOL. 55] 